\title{
LA COMPETENCIA BILINGÜE DE LOS JÓVENES EMIGRAN- TES RETORNADOS A ESPAÑA ENTRE 1986 Y 1991: APOYO SOCIAL Y REPERCUSIONES PROFESIONALES
}

\section{INTRODUCCIÓN}

Es de todos conocido que la emigración a una región o país donde se habla una lengua diferente a la del país de origen produce un detrimento paulatino en el dominio de la lengua entre los emigrantes, al menos en las generaciones sucesivas. El esfuerzo consciente hecho por parte de los emigrantes de la primera generación y, en el mejor de los casos, también por parte de las autoridades del país de origen, para mantener la lengua en las generaciones siguientes puede llegar a ralentizar el proceso de detrimento pero no consigue evitarlo con el tiempo. Después de una fase de diglosia en una o varias generaciones, la pérdida se hace casi inevitable, al menos entre la gran mayoría de los hablantes implicados. Se ha comprobado que el único factor capaz de evitar este proceso, y sólo en casos muy aislados, es la actitud positiva del joven emigrante de la segunda 0 tercera generación hacia la lengua de sus padres, pero también lo es la actitud positiva hacia la del país de llegada. Esta actitud doblemente positiva' puede inducirlo a realizar un esfuerzo consciente por cultivar ambas lenguas y asi mantener también la de sus antepasados, al menos en gran parte. Pero aún en estos casos, el mero hecho de vivir durante casi todo el año en el país de acogida, se refleja en una rique- za léxica mayor en la lengua de este pais (Käuper 2001).

Así se ha demostrado, en el caso del español entre las primeras generaciones de emigrantes españoles que fueron durante los años 60 a Alemania, en busca de una situación económica mejor (Vilar Sánchez 1995a y 1995b).

\section{LOS REMIGRANTES ${ }^{2}$}

\subsection{Situación de los remigrantes}

Al día de hoy, una gran parte de esos emigrantes de los años 60 ha regresado a su país de origen. Desde hace más de una década, venimos siguiendo el reflujo de esos remigrantes a España. En la mayoría

Karin y JuAn AntOnio primera generación han cumplido Vilar Sánchez

Universidad de Granada

Facultad de traducción E interpretación ya la edad de jubilación y por fin pueden regresar a vivir a su país. Un gran número de ellos deja a sus hijos adultos en el país de acogida, ya que es alli donde los hijos han establecido su vida, tanto desde el punto de vista profesional como familiar $y / 0$ afectivo. Sin embargo, en muchos casos se traen a los hijos más jóvenes, y casi siempre en contra de la voluntad de éstos. Los jóvenes de repente se encuentran en una sociedad que sólo conocen de las vacaciones, época que se caracterizaba por una forma de vida distendida que general- 
mente no tenía mucho que ver con la realidad en la que se encuentran ahora. Durante las vacaciones, los contactos a menudo se limitaban a la familia y los temas de conversación eran sumamente cotidianos, tal como suele pasar también en los hogares españoles en el extranjero. Por ello, los jóvenes no solian tener problemas de comunicación ni, desde luego, sufrian ningún tipo de rechazo por parte de sus interlocutores. Sin embargo, hemos observado que al regresar de forma definitiva y al tener que incorporarse a la vida social y escolar de la comunidad española, se produce un enorme choque. Las formas de convivencia social son distintas $y$, lo que es más grave, el lenguaje que se utiliza es totalmente diferente al que los jóvenes remigrantes conocen de sus hogares. De repente se enfrentan con el código elaborado de la escuela, que no sólo se caracteriza por una estructura más compleja, lo que ya significa un problema en si, sino por un vocabulario en gran parte desconocido ${ }^{3}$, debido al hecho de que se tratan temas que no suelen comentarse en sus familias ${ }^{4}$ Sin embargo, en la lengua extranjera adquirida, dicho vocabulario les es

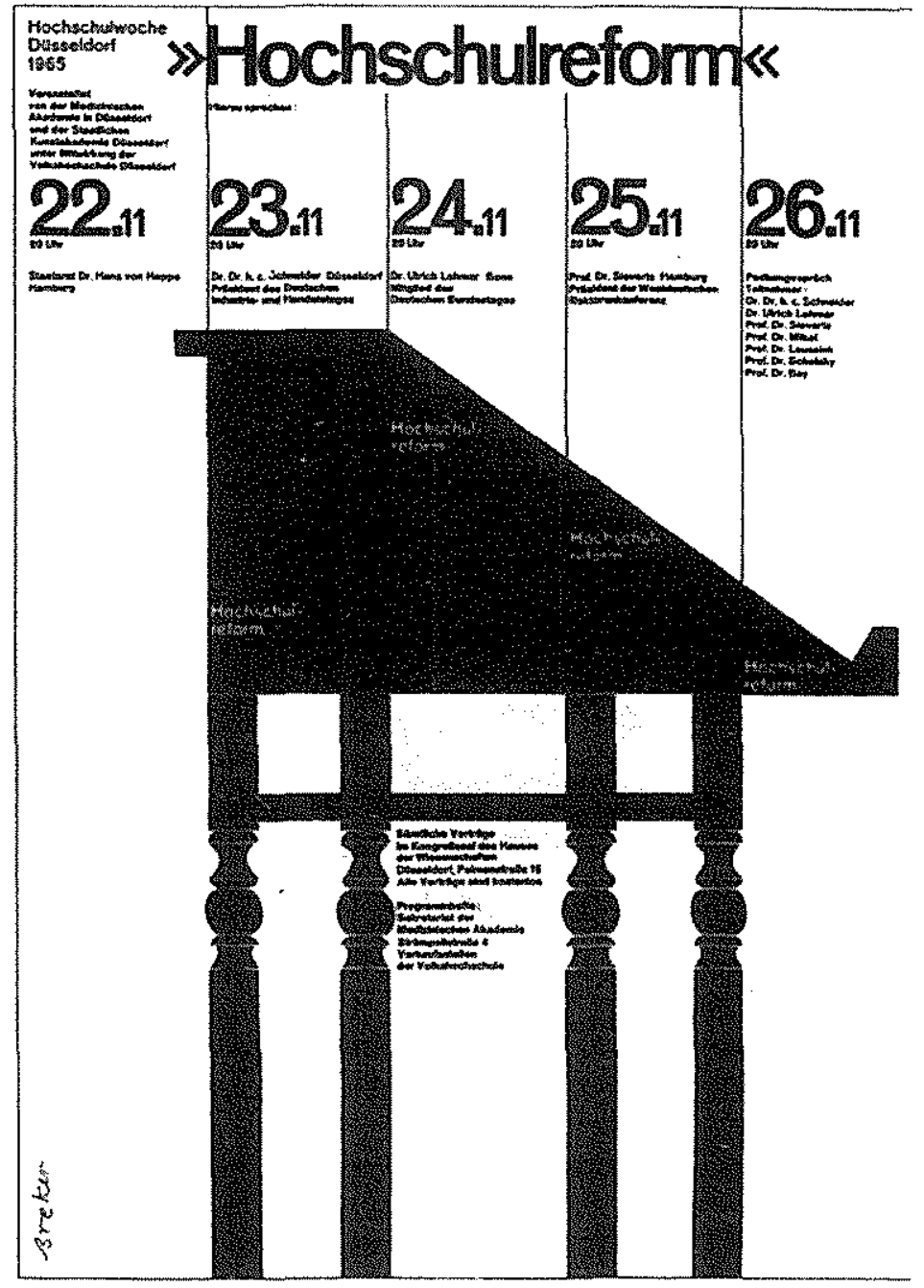
perfectamente conocido por haber tratado los temas correspondientes en la escuela del pais de acogida. Además, el mundo cultural español, el de los medios, el ámbito administrativo, el comercial, etcétera, es decir, todo el contexto social confronta a los jóvenes con un léxico desconocido para ellos y con un código no acostumbrado. Todo eso, sin duda, debe generar una enorme inseguridad en ellos. En esta situación experimentan una fuerte sensación de alienación, de desarraigo y de anomia5; paradójicamente en el país que sus padres siempre les habian descrito como el suyo, el pais al que verdaderamente pertenecen.

\subsection{La reacción del entorno}

\subsubsection{Reacción de los docentes}

A todo ello se suma la reacción de las personas de

su nuevo entorno; por un lado la de los maestros y profesores, que muchas veces no comprenden la situación de los jóvenes remigrantes. Sólo observan en los jóvenes un déficit importante de conocimientos en general y un dominio lingüístico deficiente. El problema consiste en que muchas veces los docentes no llegan a comprender que las deficiencias de conocimientos, casi siempre, se deben a la diferencia de contenidos docentes en sistemas escolares pertenecientes a paises diferentes, como son España y Alemania o Inglaterra, Francia o Suiza, y que las deficiencias lingüisticas no son el reflejo de una pobre competencia intelectual de los jóvenes sino simplemente de su situación de emigración y de diglosia ${ }^{6}$. Desgraciadamente, incluso entre la población más formada, a menudo se mantiene la
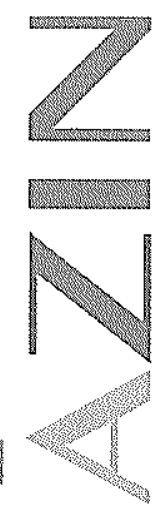
creencia de que "el que ni siquiera sabe hablar con propiedad (la lengua de su pais, se entiende) tampoco debe saber otras cosas", es decir, que no debe de ser una persona muy inteligente.

\subsubsection{Reacción del peer group}

Más importante que la posible incomprensión por parte de los docentes es la de los compañeros. Es conocido, que para la formación de la identidad de un adolescente, el grupo de amigos (peer group) es fundamental. Es en este ámbito donde el jóven se orienta y donde anhela y necesita ser reconocido. Sin embargo, como todo el mundo sabe, estos grupos se caracterizan por unos limites muy claros, y la pertenencia a ellos presupone el cumplimiento de unas normas estrictas. Además, cuanto más claros

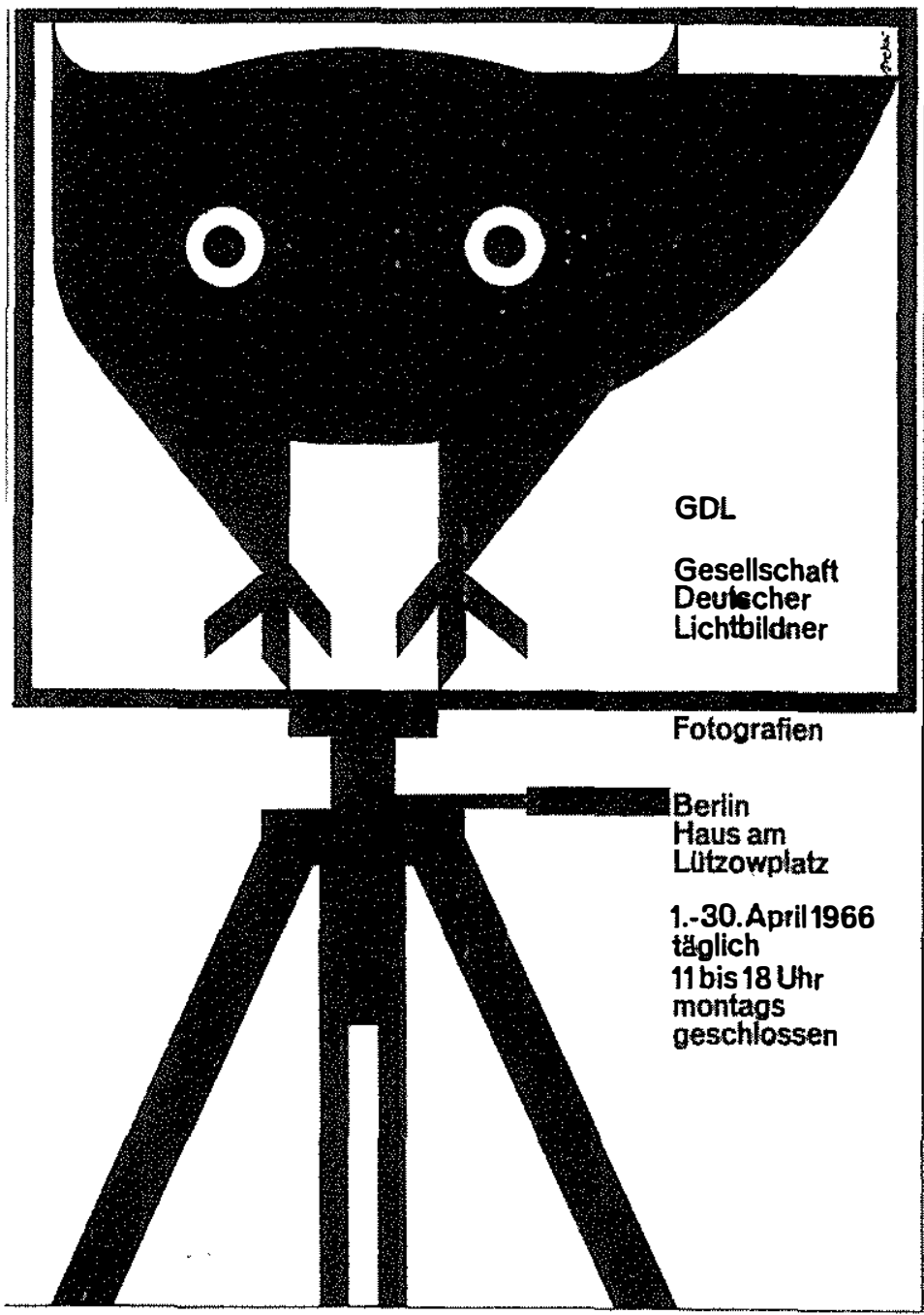

e impenetrables son los límites del grupo, más sensación de pertenencia y seguridad proporciona a sus miembros?. Tambièn se sabe, que una de las características más importantes de estos grupos sociales es su lenguaje. En el caso de los jóvenes suele desarrollarse un código juvenil que se caracteriza por un vocabulario en parte innovador y por unas estructuras, por regla general, sencillas. Su función principal es la de marcar las diferencias con el lenguaje establecido de los adultos. En todo caso, se trata de un código desconocido para los jóvenes remigrantes.

Como consecuencia, para poder pertenecer al grupo de los adolescentes, los jóvenes remigrantes han de hacer todo lo posible por adquirir las caracteristicas del grupo. Esto significa adaptarse a sus normas en todos los sentidos y aprender su código. $Y$ desgraciadamente también puede significar olvidarse de la lengua del país de donde vienen, es decir, no nombrarla en lo posible y menos practicarla en presencia de los demás miembros del grupo. Este comportamiento lógicamente lleva a un nuevo proceso de detrimento, en este caso el de la lengua del país de emigración, el alemán, inglés o francés. Muestra de ello son los numerosos jóvenes que nacieron en el país de acogida, que fueron a la escuela alli y que hablaron su idioma como lengua materna y que ahora, a consecuencia del desuso total de esa lengua en España, no se atreven ni siquiera a pronunciarse de forma extensa sobre algún tema en ella ${ }^{8}$ Lo interesante en estos casos es que, en una conversación con estos jóvenes en la lengua extranjera adquirida, al principio, no se detecta el deterioro lingüístico. Los jóvenes han desarrollado técnicas para evitar lo olvidado o compensarlo mediante el uso de las formas retenidas u otras estrategias compensatorias ${ }^{9}$ Hemos podido observar que, igual 
que en el caso del detrimento del español entre los emigrantes de la segunda generación, la pérdida lingüistica entre los remigrantes se produce de forma más acusada en el léxico, menos en el campo gramatical y nunca en el fonético.

\section{ENFOQUE ECONÓMICO}

\subsection{El conocimiento de una lengua extranjera como capital humano}

Cada vez mas, aumenta la conciencia de que el conocimiento de una lengua extranjera supone un importante capital humano, igual que otras competencias intelectuales, manuales o técnicas ${ }^{10}$. Prueba de ello es el gran esfuerzo que realizan los profesionales y las personas en formación por adquirirlo. Éstos, cada vez mas, asumen importantes costes económicos y de tiempo en dicho empeño, ya que saben que el conocimiento de una o varias lenguas extranjeras puede aumentar de forma considerable sus posibilidades de promoción profesional en todos los sectores económicos, tanto en el turístico, que es uno de los sectores principales de la economía española, como en los demás (agricultura, servicios, industria, etc.). Todos ellos se caracterizan por una globalización cada vez mayor. Aparte de las ventajas profesionales y por ende económicas, los individuos esperan beneficios intelectuales y de aceptación social. En este sentido, el inglés como lingua franca tiene una posición privilegiada. Sin embargo, en España, también el alemán, debido a su importancia en el sector turístico y en el comercial, y a pesar de las supuestas dificultades por aprenderlo, está ganando cada vez mas terreno. El número de alumnos que estudian ambas lenguas en España aumenta de forma continua, tanto en la educación pública como en la privada (a todos los niveles) y en la autodidacta. Se podria decir que aprender lenguas extranjeras está de moda en España.

\subsection{El capital de los remigrantes}

Ahora bien, mientras que unos luchan por adquirir conocimientos en otras lenguas con el fin de mejorar su estatus socioeconómico, con unos resultados en ocasiones bastante humildes, aunque no siempre, otros, los remigrantes, luchan por adaptarse a la forma de hablar de sus nuevos amigos y entorno, con el fin de pertenecer al grupo, asumiendo al

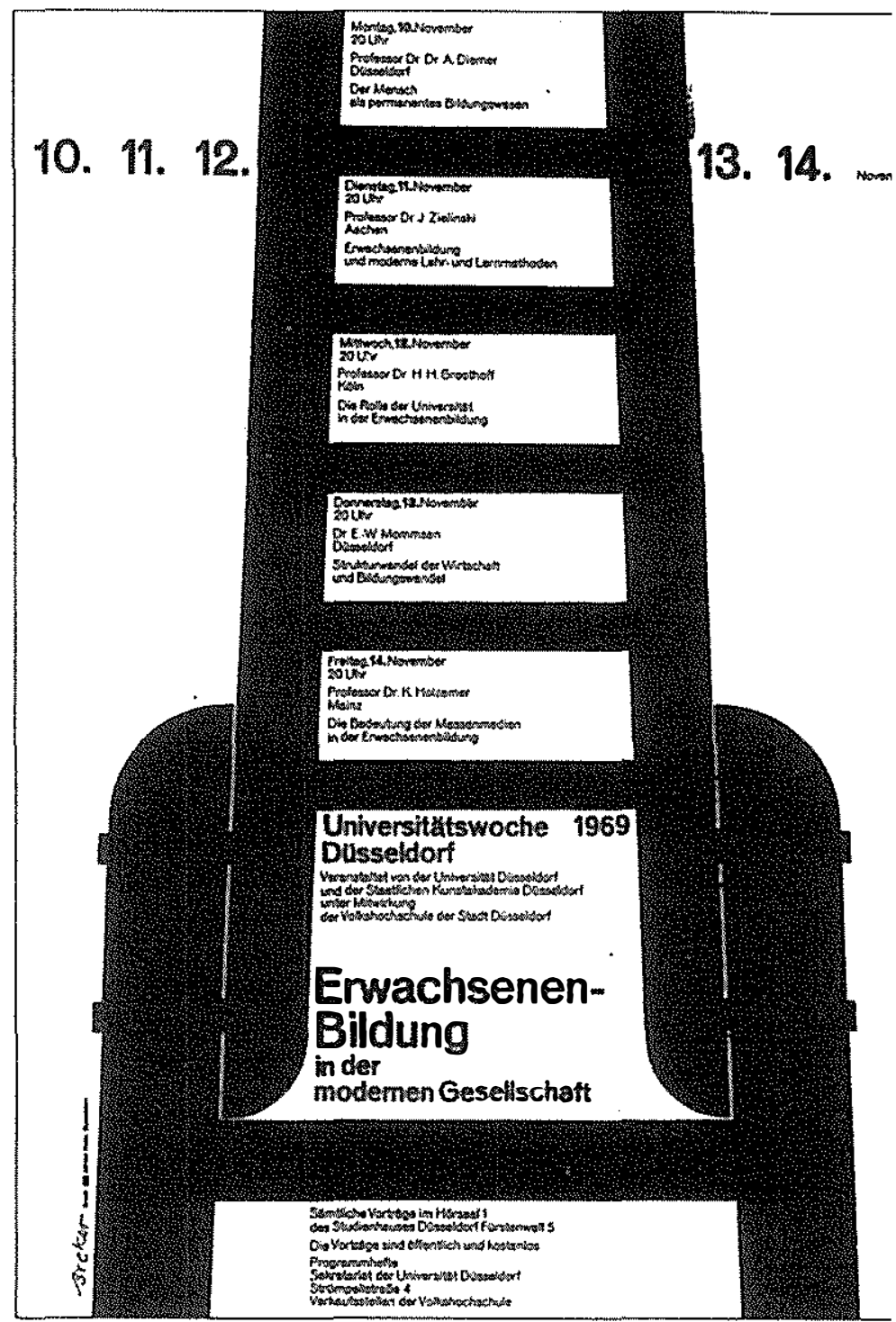

mismo tiempo el detrimento de la lengua adquirida en el extranjero. Incluso los padres de estos jóvenes parten de la base de que las deficiencias de sus hijos en español los llevará a una desventaja en el ámbito escolar y luego en el mundo laboral. En ello a menudo olvidan que sus hijos poseen un capital humano importante que es el conocimiento de esa lengua extranjera. Son conocimientos nativos que un no nativo prácticamente nunca podrá adquirir en todas sus facetas, a no ser que invierta unos esfuerzos enormes. Naturalmente, en muchos casos el factor emocional también juega un papel importante en la actitud de los padres, concretamente la ale-

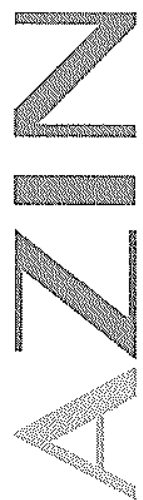




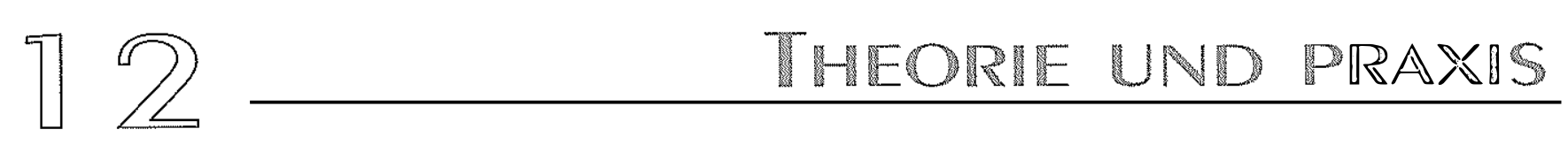

gria de haber vuelto a su país y el empeño por integrar a sus hijos de la forma más rápida posible en la sociedad circundante y a veces incluso el deseo de olvidar el pasado en el extranjero.

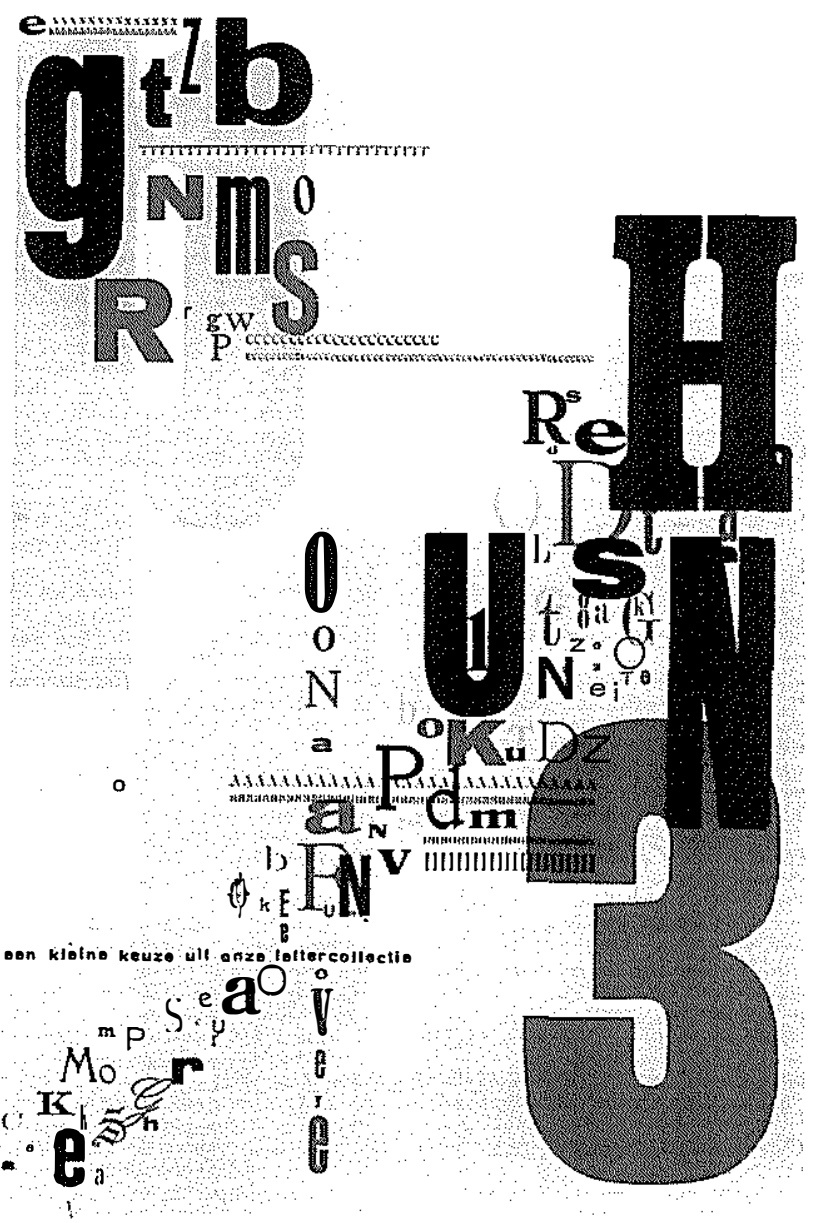

Para romper esta visión miope ${ }^{11}$ tanto de los jóvenes remigrantes mismos como de sus padres, es imprescindible concienciarlos del capital lingüístico que poseen. Han de comprender que se trata de un recurso que les puede abrir muchas puertas si saben cuidarlo, fomentarlo y utilizarlo. Para ello hace falta informarles de las posibilidades profesionales que estos conocimientos brindan, de forma indirecta o incluso directa. En términos económicos, hay que hacerles comprender que la inversión que realizaron mediante el sacrificio de abandonar su pais para mejorar su situación económica, aparte de los ingresos monetarios, les ha brindado otros beneficios importantes en las personas de sus hijos. Y es precisamente este capital humano que supone el conocimiento profundo de una lengua extranjera. Además, y esto es muy importante, hay que hacerles ver que ello no significa de ninguna manera que los jóvenes no se integren en su ámbito actual. Es preciso que comprendan que una identidad cultural y lingüistica doble es posible, que puede ser muy enriquecedora y de ninguna forma ha de ser sustractiva y empobrecedora. Con todo, se trata de realizar una labor de concienciación entre los jóvenes remigrantes, entre sus familias, entre los profesores y en la sociedad en general.

\section{EL PROYECTO}

\subsection{Introducción}

Para poder llevar a cabo esta labor de concienciación y con el fin de comprobar de manera empírica todos los supuestos anteriores, los autores del presente articulo, en el marco del Año Europeo de las Lenguas 2001, solicitamos en su tiempo apoyo económico a la Unión Europea y, como condición previa para esta solicitud, a diversas instituciones españolas, para la realización de un proyecto de investigación. Las instituciones que han confirmado su colaboración son, por un lado, el Ministerio de Trabajo español y más concretamente la Dirección General de Migraciones $y$, por otro, la Consejeria de Asuntos Sociales de la Junta de Andalucia. Sin embargo, el proyecto no ha sido aceptado como tal por la UE por dirigirse a un público demasiado especifico. A pesar de ello, el proyecto se llevará a cabo a partir del mes de octubre de este año 2001, con el apoyo exclusivo de las instituciones españolas. Los miembros del equipo pertenecen o bien a la Universidad de Granada o a la Asociación Granadina de Emigrantes Retornados.

\section{2. Objetivos del proyecto y actividades prin- cipales}

El grupo concreto de remigrantes que nos permitirá reunir información para realizar el estudio propuesto, es el de los jóvenes retornados a España entre 1986 y 1991 y que en aquel momento tenian entre 10 y 14 años. De esta forma se garantiza que los informantes hayan recibido parte de su formación escolar y/o profesional en el país de llegada y parte en el de salida. Además, el intervalo de 10 años, entre 1991 y 2001, permite analizar el desarrollo personal y profesional posterior. El presupuesto del proyecto nos permitirá entrevistar a unos 100 informantes dentro de la provincia de Granada, una de las mas afectadas por la emigración en los años 60 .

El primer bloque de preguntas de nuestras entrevistas personales tiene como objetivo reunir información acerca de la situación personal y escolar de los jóvenes, inmediatamente después de su llegada a 
España hace al menos 10 años. En este sentido nos interesa por un lado la actitud que mostraron hacia ellos y su situación especial sus amigos, compañeros de clase, maestros y profesores, y la sociedad en general $y$, por otro queremos conocer su estado emocional personal en esta situación, es decir, grado de satisfacción por encontrarse en España y haber dejado atrás el pais de acogida, y posibles sensaciones de euforia o, al contrario, de desarraigo o alienación.

A continuación y durante la misma entrevista, nos informaremos de la situación personal y laboral presente de los mismos individuos y de su grado de satisfacción con esta situación actual: nivel de formación, puesto de trabajo, situación económica, perspectivas para el futuro, etc.

Esta información obtenida en las entrevistas personales con los remigrantes, nos permitirá comprobar la existencia de relaciones causales entre el apoyo o rechazo social hacia su bilingüismo y biculturalismo recibido a la hora de regresar, y su desarrollo profesional posterior.

Los resultados de nuestro estudio serán publicados en diversos medios de comunicación (prensa, radio y televisión regional) con el fin de informar a la sociedad sobre los beneficios personales y económicos que conlleva ese bilingüismo y biculturalismo, para el individuo implicado y para la sociedad en la que vive, y a la que enriquece con su bagaje cultural y lingüístico. Asimismo se hará hincapié en el error de rechazar esta doble pertenencia cultural y lingüística, y las desventajas que conlleva este rechazo para el individuo $y$, por ende, para la sociedad en general. Es importante que la sociedad aprenda a entender el fenómeno de la movilidad de los individuos entre los paises como una actividad enriquecedora y natural que conduce al bienestar personal y social.

Por último, planeamos la publicación de una monografía dirigida especialmente al colectivo de los responsables de la educación. El objetivo es sensibilizarlos para que faciliten la adaptación de los jóvenes que vuelven a su pais de origen, teniendo en cuenta y valorando positivamente su doble bagaje cultural y lingüístico, y para que les ayuden y dirijan hacia el fomento y aprovechamiento profesional de dicha competencia ${ }^{12}$.

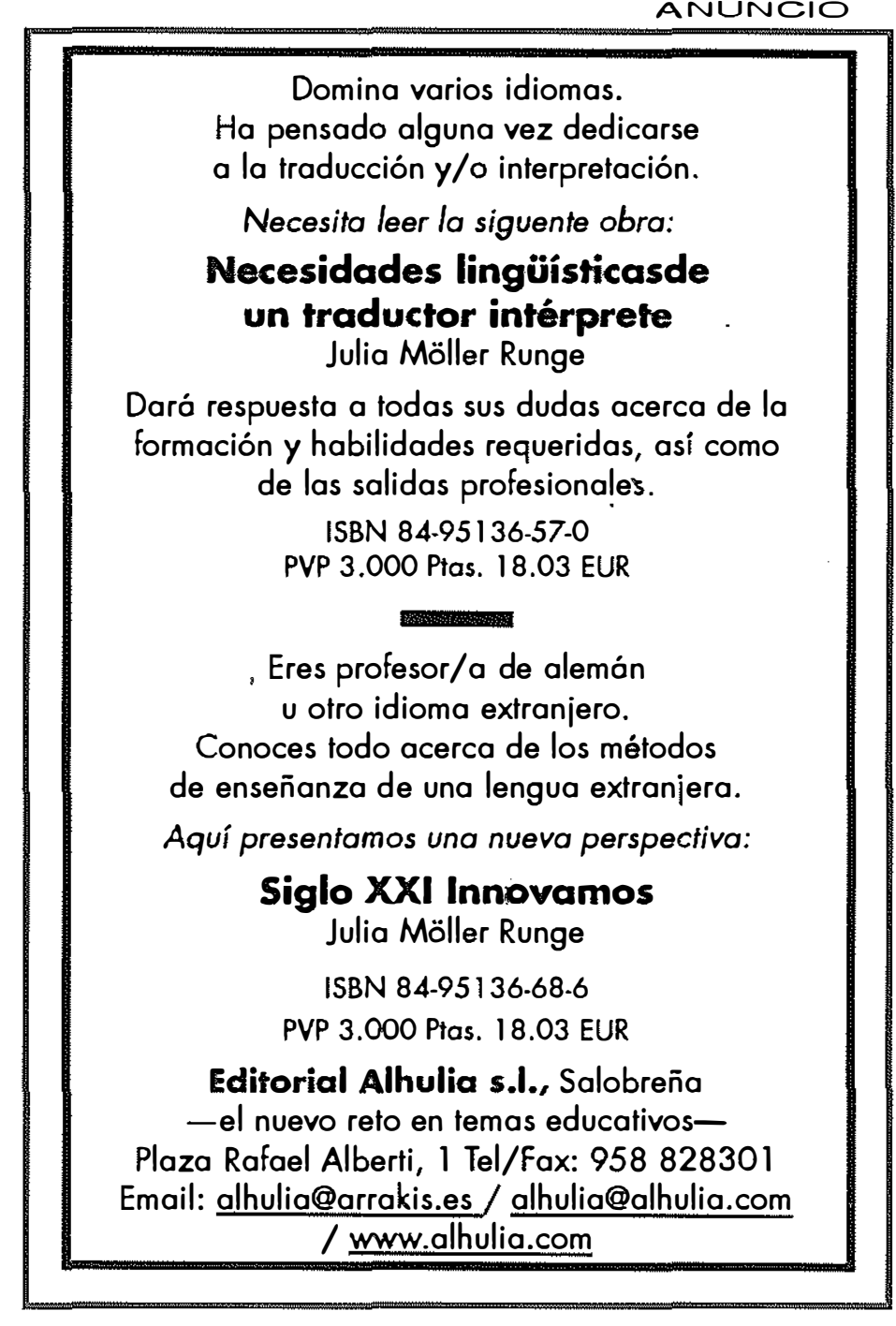

\section{CONCLUSIONES}

Si conseguimos poner en marcha los cambios de actitud arriba descritos, se evitará la pérdida progresiva de una enorme riqueza cultural y lingüistica adquirida, lo que no sólo contribuirá a mejorar la situación personal y profesional de los remigrantes y de la sociedad en general, sino tambièn a la construcción de una Europa Unida. Estos individuos y todos los europeos que en el futuro emigren dentro de Europa, aunque ya no sea tanto por necesidad sino por voluntad propia, podrán actuar como auténticos puentes entre los paises, ya que su propia historia personal les ha permitido formar parte integral de varios de ellos.

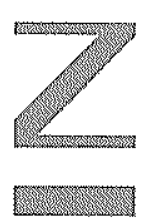

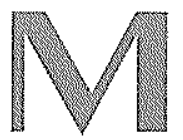
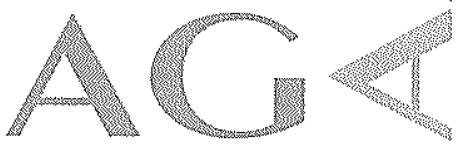
RESUMEN DEL PROYECTO DE INVESTIGACIÓN, SUBVENCIONADO POR LA JUNTA DE ANDALUCÍA, CONSEJERÍA DE ASUNTOS SOCIALES ${ }^{13}$ :

Es un hecho demostrado que la actitud de la persona frente a una cultura y su lengua determina en gran medida su capacidad para aprender, hablar y mantener dicha lengua. Esto es válido para el emigrante que reside en el extranjero (vid. Vilar Sánchez: 1992) y también para el que vuelve a su pais de origen. Cuando el emigrante regresa a su tierra, la de enfrentarse con valoraciones muy distintas de su doble bagaje cultural y lingüistico, por parte de la sociedad. Según nuestras observaciones, una actitud positiva de la sociedad, y especialmente del entorno escolar, repercute positivamente en el mantenimiento de la lengua extranjera y en el aprovechamiento profesional de la misma. Por contrario, la actitud negativa de dicho entorno conduce al rechazo total de la cultura y lengua adquirida en el extranjero $y$, como consecuencia, a la pérdida progresiva de una posible fuente de riqueza y bienestar.

Es la intención de este proyecto comprobar dicha interdependencia y publicar los resultados del estudio con un doble fin:

A) sensibilizar a la población y en especial a los responsables de educación para que faciliten la adaptación de los jóvenes que regresan a su pais de origen, teniendo en cuenta y valorando positivamente su doble bagaje cultural y lingüistico;

B) sensibilizar al mismo colectivo para que ayuden y dirijan a los mismos jóvenes hacia el fomento y aprovechamiento profesional de dicha competencia.

\section{Objetivos:}

a. Conocer la situación personal y escolar de los jóvenes emigrantes retornados a España entre 1985 y 1990, inmediatamente después de su llegada.

b. Conocer su situación personal y laboral presente.

c. Comprobar la existencia de relaciones causales entre el apoyo o rechazo social hacia su bilingüismo y biculturalismo recibido a la hora de regresar, y su desarrollo profesional posterior

d. Publicar los resultados, con el fin de sensibilizar a los responsables de educación para que faciliten la adaptación de los jóvenes que vuelven a su país de origen, teniendo en cuenta y valorando positivamente su doble bagaje cultural y lingüístico, y para que les ayuden y dirijan hacia el fomento y aprovechamiento profesional de dicha competencia.

e.Concienciar a la población para que entienda el fenómeno de la movilidad entre los paises como una actividad enriquecedora y natural que conduce al bienestar personal y social.

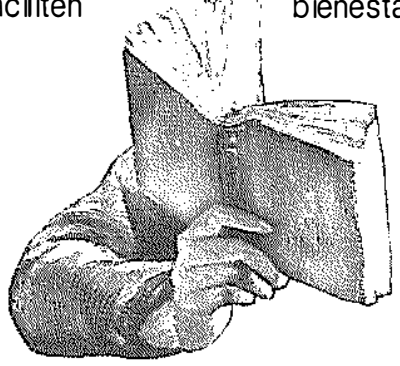

\section{BIBLIOGRAFÍA}

-BLOOM, D. E. Y G. GRENIER (1992) "Economic Perspectives on Language: The Relative Value of Bilingualism in Canada and the United States", en: Crawford, J. (ed.) Language Loyalties: A Source Book on the Official English Controversy, University of Chicago Press, Chicago, pp. 445-451.

-Idem (1996) "Language, employment, and earnings in the United States: Spanish-English differentials form 1970 to 1990", en International Journal of the Sociology of Language, 121, pp. 45-68.

-FÄrCH Y KASPER (1980) "Processes and Strategies in Foreign Language Learning and Communication", Interlanguage Studies Bulletin, 5, pp. 47-118.

-GLLES, H., BouRHIS, R. y D. TAYLOR (1977) "Towards a Theory of Language in Ethnic Group Relations", en: Giles, H. (ed.): Language, Ethnicity and Intergroup Relations, Academic Press, London.

-GLES, H. Y P. JOHns ON (1981) "The Role of Language in Ethnic Group Relations", en: Turner y Giles (eds.) Intergroup Behaviour, Oxford, pp. 199-243. 
-KäUPer, ANJa y Carlos Guerrero Ramos (2001) "Mantenimiento y pérdida del español entre los emigrantes de segunda generación en Alemania", en: Actas del III Congreso nacional de la FAGE. (en prensa)

- VILAR SÁnchez, Karin (1995a) Lengua y Emigración. Publicaciones de la Cátedra de Historia de la Lengua Española. Series Lingüistica. Servicio de publicaciones de la Universidad de Granada, Granada.

-Idem (1995b) "For Want of the Standard Educated Variety of Spanish ... A German Accent: A Sociolinguistic Case Study", en: International Journal of the Sociology of Language (IJSL), 116, pp. 5-16.

İdem (1998) "Diglossische Prozesse (zwischen Deutsch und Spanisch) unter den spanischen Emigranten der 2. Generation in Deutschland: eine soziolinguistische Studie", en: International Review of Applied Linguistics in Language Teaching, XXXVI/3, pp. 197-212.

\section{NOTAS}

1. En contra de todas la expectativas, la actitud positiva unilateral hacia la lengua de los padres junto con el rechazo de la lengua del pais de acogida, no ha demostrado llevar a un dominio satisfactorio de la lengua de origen sino a un semilingüismo en ambas lenguas.

2. Utilizaremos el término remigrante para denominar al emigrante retormado a su pais de origen.

3. Si bien es cierto que algunos de los remigrantes tuvieron la posibilidad de asistir a clases de español en Alemania.

4. En casi todos los casos los padres pertenecen a la clase trabajadora y no disponen de estudios. Además, la mayoria de ellos proviene de núcleos rurales y vuelve a ellos.

5 .Estado de integración social deficiente dentro de un grupo social. La estabilidad de las relaciones sociales está perturbada y las normas institucionales han perdido su función determinante del comportamiento de los individuos. Se trata, en general, de una pérdida de normas sociales.

6.A ello hay que añadir el hecho de que los jóvenes solian estar expuestos exclusivamente a una variante dialectal del español y que no dominaban en gran parte el castellano generalmente aceptado para la comunicación entre hablantes de todas las regiones de España.

7.Los limites del grupo son uno de los tres factores que determinan el deseo del individuo de pertenecer a un grupo etnolingüistico. Los otros dos factores son la vitalidad etnolingüistica percibida (estatus económico, político y de prestigio politico, los factores demográficos y el apoyo institucional) y la pertenencia del individuo a varios grupos diferentes. Vid. Teoria de la identidad etnolingüistica en Giles y Johnson 1981.

8.En nuestro trabajo en la Facultad de Traducción e Interpretación de la Universidad de Granada y también en las dependencias de la Asociación Granadina de Emigrantes Retormados tenemos la oportunidad de hablar con muchos de estos jóvenes remigrantes.

9.Vid. Färch et al. 1980 y Vilar Sánchez 1995a: 305-355.

10.Bloom y Grenier 1992 y 1996 entienden el conocimiento de una lengua como capital humano, es decir, como un factor que aumenta el valor del individuo en el mercado laboral, igual que otras habilidades o competencias.

11.Esta metáfora hace referencia al hecho de que a los jóvenes, igual que a los individuos pertenecientes a clases sociales más humildes en general, les cuesta más posponer el disfrute de los beneficios de una acción y tienden a elegir la satisfacción o el placer inmediato; muchas veces a costa de unos beneficios mayores.

12.Para poder llevar a cabo esa labor orientadora, los docentes mismos, con anterioridad, han de recibir información sobre las salidas profesionales que brinda el conocimiento de una o varias languas extranjeras.

13. Subvencionada en el marco del Programa 19: "Ayudas para el desarrollo de proyectos concretos en el ámbito migratorio" promovido por la Dirección General de Ordenación de Migraciones, en aplicación de la orden de 29 de agosto de 2000 (BOE de 14 de Septiembre de 2000) del Ministerio de Trabajo y Asuntos Sociales. Subvencionada por la Delegación Provincial de Asuntos Sociales de Granada, mediante ayuda pública correspondiente a la convocatoria efectuada por la Orden de 3 de Enero de 2001.

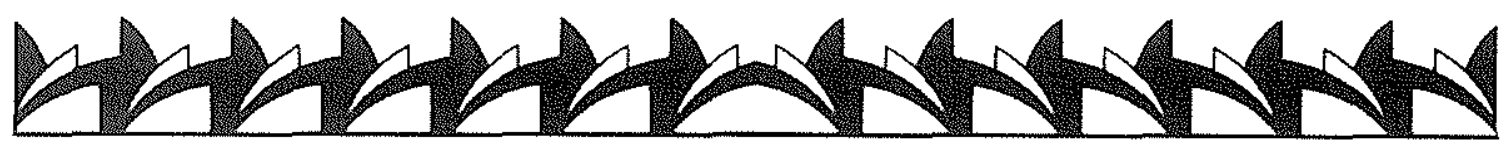

